\title{
La intervención del derecho de patronazgo en las disputas entre jurisdicciones eclesiásticas: la colegiata de Aguilar de Campoo y el arzobispo de Burgos en 1748*
}

The intervention of the patronage rights in disputes between ecclesiastical jurisdictions: the Collegiate Church of Aguilar de Campoo and the Archbishop of Burgos in 1748

\author{
Alberto CORADA ALONSO \\ Instituto Universitario de Historia Simancas \\ Universidad de Valladolid \\ https://orcid.org/000o-0002-6396-4574 \\ acarf_aguilar@hotmail.com
}

\begin{abstract}
The present paper is an attempt to underscore a question that affected all levels of the Church's structure: jurisdictional conflicts. In this case, we shall focus on one of the critical junctures in the tension existing between the Collegiate Church of Aguilar de Campoo and the Burgos' bishopric. Although both institutions quarrelled about jurisdictional issues during most of the Modern Era, there were moments when the level of violence reached such degree that called for the intervention of different judicial authorities and, at last, for the intervention of the lay patron of the Collegiate Church, the only one who could fix the difficult situation.
\end{abstract}

Keywords: Jurisdictional conflict; Modern Era; Collegiate Church of Aguilar de Campoo (Palencia); Archbishop of Burgos.
Resumen: Con este trabajo se pretende poner de relieve una realidad que afectaba a todos los niveles jerárquicos del organigrama de la Iglesia: los conflictos jurisdiccionales. En este caso concreto se presenta uno de los puntos álgidos de la tensión vivida entre la colegiata de Aguilar de Campoo y la mitra burgalesa. Aunque ambas instituciones estuvieron enfrentadas por cuestiones jurisdiccionales durante buena parte de la Edad Moderna, hubo momentos en que los acontecimientos alcanzaron cotas de violencia que hizo necesaria la intervención de diferentes autoridades judiciales y, finalmente, de la figura del patrón laico de la colegial, que fue el único capaz de reconducir la situación.

Palabras clave: conflicto jurisdiccional; Edad Moderna; colegiata de Aguilar de Campoo (Palencia); arzobispo de Burgos.

* Miembro del equipo de trabajo del Proyecto «Justicia, mujer y sociedad de la Edad Moderna a la Contemporaneidad. Castilla, Portugal e Italia» (HAR2016-76662-R; Proyectos de I+D+I, correspondientes al Programa Estatal de Investigación, Desarrollo e Innovación orientada a los Retos de la Sociedad, en el marco del Plan Estatal de Investigación Científica y Técnica y de Innovación 2013-2016, AEI/FEDER, UE). Investigador colaborador del CHSC (Centro de História da Sociedade e da Cultura - Faculdade de Letras da Universidade de Coimbra). 


\section{INTRODUCCIÓN}

Una de las principales características de la sociedad del Antiguo Régimen europeo fue la existencia de jurisdicciones diferenciadas. La pertenencia a un grupo que contase con su propio fuero y, por lo tanto, sus propios jueces y tribunales, era un símbolo que marcaba claramente una situación jurídica de privilegio.

De todas ellas, la jurisdicción eclesiástica fue, quizás, una de las más presentes y complejas dentro del occidente católico, aunque, en realidad, no es posible hablar de ella de una forma uniforme. Los diferentes niveles jerárquicos de la Iglesia y las distintas instituciones que componían su vasta estructura gozaban de privilegios especiales y, muchas veces, excluyentes entre sí. Esto provocó, evidentemente, que existiera en el seno de la Iglesia una serie de enfrentamientos entre los diferentes niveles jurisdiccionales y que las audiencias pontificias y diocesanas, muchas veces, se saturasen de pleitos en los que se intentaba delimitar o forzar las pautas establecidas por las normas o bulas que conformaron el derecho canónico o por cualquier otro documento acreditativo de competencias y regalías.

De igual modo, no es posible obtener un análisis completo de un acto violento en la Edad Moderna si no se comprenden en profundidad las causas del mismo, las personas que lo protagonizaron, su extracción social y, sobre todo, su estatus socio-jurídico. En un mundo marcado tan profundamente por la diferencia y el privilegio no cabía esperar una justicia igual para todos. Así pues, y como se ha señalado, dentro de toda esta situación jurídica diferenciada hay que señalar de una manera muy especial la justicia y los tribunales eclesiásticos y, por consiguiente, el estatuto jurídico que protegía a los miembros del estamento clerical, es decir, su fuero.

Un fuero que suponía, ni más ni menos, una cesión de la jurisdicción real y pontificia, es decir, una jurisdicción privativa o especializada que otorgaba al clero la posibilidad de tener sus propios tribunales. La Iglesia fue, además, la única jurisdicción distinta de la del Estado que permaneció al comenzar la Edad Contemporánea -tras las Cortes de Cádiz- junto a la militar, quedando suprimidas todas las demás, con lo que se eliminaron algunos de los rasgos más característicos del sistema político y jurídico del Antiguo Régimen.

Todas esas jurisdicciones privativas entendían en asuntos judiciales que les eran propios, sin que ello significase que dicha realidad estuviera exenta de problemas. Los conflictos de competencias con la justicia real ordinaria fueron una tónica general, lo que comúnmente originaba una violencia en los tribunales donde dos o más jurisdicciones hicieron fuerza en conocer los mismos asuntos, considerándose recíprocamente una intromisión en asuntos propios y una merma 
de su poder judicial ${ }^{1}$. Así pues, la pugna competencial en este ámbito fue constante, como lo fue en otros muchos fueros jurisdiccionales, teniendo la Iglesia armas propias, meramente eclesiásticas -y no solo jurídicas- a su alcance para forzar su actuación, como fue el reiterado recurso a la excomunión ${ }^{2}$.

Por lo tanto, se entiende al clero como un estamento privilegiado, no ya solo en un aspecto de posición socioeconómica -aunque esta realidad tuvo unas diferencias internas más que notables, no pudiendo compararse nunca a los grandes prelados con los curas párrocos del mundo rural-, sino también en un aspecto jurídico, una realidad que no siempre ha sido tan conocida y comprendida como pueda parecer.

El grupo de privilegiados que se va a analizar en este estudio corresponde a una sección del clero secular existente en los reinos hispánicos durante toda la Edad Moderna. Por un lado, un alto prelado de la Iglesia hispana, el metropolitano de Burgos, y, por el otro, parte de ese clero capitular -en concreto el de la colegiata de San Miguel de Aguilar de Campoo- que, evidentemente, gozaba del fuero propio de todos los miembros de su estado. Un privilegio o aforamiento que no era otra cosa que la vinculación existente entre una persona «con la competencia de un Tribunal para ejercer jurisdicción sobre ella», es decir, una relación bilateral entre el Tribunal y el justiciable³. Según José Manuel PérezPrendes, lo que caracteriza al primero era el poder que disfrutaba dicha institución para conocer en una causa determinada, mientras que lo prioritario para el aforado era el poder negar legítima y firmemente competencias sobre uno mismo a cualquier Tribunal que no fuese aquel que defendía y encarnaba de forma perfecta su propio fuero ${ }^{4}$.

1 José de COVARRUBias, Máximas sobre recursos de fuerza y protección, con el método de introducirlos en los tribunales, Madrid, 1786, pp. 1-34.

2 Algunos autores consideran que la excomunión se utilizó tanto por los tribunales eclesiásticos que llegó a perder su eficacia durante la Edad Moderna, entendiéndose más como una cuestión burocrática de dichos tribunales que otra cosa: «La evolución de la excomunión fue clara, hasta el punto de que se puede hablar de una progresiva "judicialización” de esta censura, que se convirtió en un engranaje clave de los procedimientos contenciosos [...]. Esto no impidió, en todo caso, que desapareciesen ciertas irregularidades en su uso. Se puede afirmar, y en ello inciden tanto las fuentes del periodo bajomedieval como los sínodos de la Edad Moderna, que adquirió un cierto carácter "trivial" puesto que se abusó de su empleo» (Francisco Luis RiCO CaLLADO, La documentación judicial eclesiástica en la Edad Moderna. Estudio diplomático de los fondos diocesanos, Cáceres, 2014, p. 69).

3 José Manuel PÉREZ-PRENDES y MUÑOZ DE ARRACO, El Tribunal eclesiástico (sobre el aforamiento y la estructura de la Curia diocesana de justicia), en Enrique MARTÍNEZ RUIZ y Magdalena de PAZZIS PI (eds.), Las jurisdicciones, Madrid, 1996, p. 146.

4 Ibidem. 
Además, aquel que osaba ejercer la violencia, ya fuera verbal o física, en contra de uno de estos aforados eclesiásticos estaba no solo cometiendo una infracción legal, sino también un sacrilegio que ponía en peligro la vida de su alma inmortal. En cambio, cuando la violencia era ejercida por un clérigo, es decir, un aforado, el juicio y causa ejecutado por su delito se veía minimizado por el hecho de tener la potestad de ser juzgado por un tribunal propio compuesto por sus iguales, si no en lo social y económico como ya se ha dicho con anterioridad, al menos sí en lo jurídico y procesal ${ }^{5}$.

El problema venía, en cambio, cuando el enfrentamiento se producía entre dos jurisdicciones eclesiásticas, máxime si este desembocaba en procesos de violencia. Los sucesos de 1748 en la colegiata de Aguilar de Campoo muestran uno de esos momentos en los que ambas potestades religiosas pusieron en marcha, como consecuencia, toda su maquinaria judicial y jurisdiccional para intentar mantener sus posiciones y defender unas exenciones que consideraban de total validez y de enorme importancia.

En situaciones así fue normal que se produjera la intromisión de otras potestades y, en este caso concreto, el conflicto desatado solo se logró solucionar con la decisiva intervención de los marqueses de Aguilar de Campoo. Estos aristócratas ejercieron su enorme poder de patronazgo sobre la colegiata y desplegaron su prestigio frente al ordinario para llevar a cabo una mediación necesaria que permitió constatar, de nuevo, la dificultad de los equilibrios jurisdiccionales en el Antiguo Régimen.

\section{LA COMPLEJA REALIDAD DE LA ARCHIDIÓCESIS DE BURGOS}

La archidiócesis de Burgos tuvo a lo largo de la Edad Moderna unas características realmente especiales ya que, debido a su propia evolución, había surgido en su seno una gran multitud de poderes eclesiásticos diferenciados, muchos de ellos enormemente celosos de sus fueros y exenciones ${ }^{6}$.

5 Alberto Corada Alonso, Fuero y violencia: el clero capitular ante la Audiencia Abacial de Aguilar de Campoo, en Paula Hernández RodríGuez et al. (eds.), Las Violencias y la Historia, Salamanca, 2016, pp. 788-789. Es preciso señalar, no obstante, que esta era una norma general pero no absoluta, pues en algunos casos este privilegio concedido quedó restringido por los «soberanos a favor del bien común». José de COVARRUBIAS, Máximas sobre recursos de fuerza... [ver n. 1], pp. 88-89.

6 Alberto CORADa Alonso, Burgos: una diócesis en conflicto durante el Antiguo Régimen, en Ofelia Rey CastelaO, Rubén CASTRO REDONDO y Camilo FERnández CoRTizo (eds.), La vida inquieta. Conflictos sociales en la Edad Moderna, Santiago de Compostela, 2018, pp. 197-213; Alberto 
Dentro de toda esa amalgama de jurisdicciones existentes, el gran contrapoder al que tuvo que hacer frente el arzobispo de Burgos dentro de su ámbito jurisdiccional, y el mayor freno a su actividad de gobierno, vino de la mano del cabildo catedralicio, una institución que para algunos historiadores fue, sin ninguna duda, la «más importante de la historia de la diócesis burgalesa»7.

No obstante, los enfrentamientos jurisdiccionales de los ordinarios de Burgos no se limitaron, como es lógico, a las luchas intestinas con su cabildo, sino que otras iglesias de su diócesis, especialmente las colegiatas, importunaron sobremanera la correcta función de gobierno y administración de estos prelados. Estas instituciones, a medio camino entre una iglesia parroquial y una catedral, y ya fueran de origen medieval o de fundación moderna, acapararon paulatinamente rentas y, sobre todo, privilegios y poderes jurisdiccionales que supusieron un verdadero quebradero de cabeza para los prelados burgaleses. Además, debido al desarrollo histórico de la diócesis, el número de colegiatas fue bastante elevado, oscilando entre las trece que se señalan en la visita ad limina de 1636 y las diez en la de $1795^{\circ}$.

Todas ellas se constituyeron en sus territorios como un verdadero poder local y un contrapeso a la autoridad episcopal. Lerma, por ejemplo, se conformó como un territorio vere nullius separado de la diócesis. Santander, por su parte, debido a lo alejado que se encontraba de Burgos y a la difícil orografía del territorio -de la que se derivó una clara desatención pastoral- pugnó desde el siglo XVI por conseguir su elevación a rango de catedral, con la consiguiente creación de una diócesis separada de la mitra burgalesa. Y, por poner otro ejemplo, la colegiata de Aguilar mantuvo durante gran parte de la Edad Moderna pleitos con los arzobispos para delimitar el alcance de las competencias de la audiencia del abad en materia civil y, sobre todo, criminal.

Sin embargo, la mayor queja que se elevó a Roma por un prelado de Burgos fue la que hizo Juan Francisco Guillén en su relación ad limina de 1754, un infor-

CORADA AlONSO, La archidiócesis de Burgos a través de las Visitas ad limina de finales del Antiguo Régimen: gobierno y organización interna, en $M^{a}$ Ángeles PÉREZ SAMPER y José Luis BETRÁN MOYA (eds.), Nuevas perspectivas de investigación en Historia Moderna: Economía, Sociedad, Política y Cultura en el Mundo Hispánico, Madrid, 2018, pp. 342-353.

7 Alberto PaCho Polvorinos, Edad Moderna, en Bernabé Bartolomé MartíneZ (ed.), Historia de las diócesis españolas, vol. 20. Iglesias de Burgos, Osma-Soria y Santander, Madrid, 2004, pp. 123188.

8 Estas colegiatas fueron las de Valpuesta, Briviesca, Castrojeriz, Cervatos, San Quirce, San Millán de Lara, Santillana, Santander, Aguilar de Campoo, Lerma, San Martín de Elines, Santa Cruz de Castañeda y Covarrubias. Roma. ARChivio Apostólico VATICANO [=AAV], Congr. Concilio, Relat. Dioec., caja 156, Visitas de 1636 y de 1795. 
me en el que se contenían relatos sobre fuertes conflictos con cuatro colegiatas, aunque con un apartado especial dedicado a la de Aguilar de Campoo. Guillén informó que había visitado en persona dicha colegiata, obligado como estaba por uno de los muchos privilegios de la institución colegial. Aun así, y aunque se había llevado a cabo la visita con paz y quietud, reconoció que tuvo que disimular y hacer «la vista gorda a muchas cosas en punta de jurisdicción y preeminencias que practica el abad sin tenerlas» ${ }^{9}$. Sin embargo, las tensiones con Aguilar venían de lejos y tenían mucho arraigo. Según informó el arzobispo, y como se ha podido constatar por otras fuentes ${ }^{10}$, en la visita realizada a la colegiata por su antecesor no hubo tanta normalidad, cometiendo tanto el abad como la villa de Aguilar muchos excesos,

hasta pasar a poner presso al notario que embió el arzobispo para que compulsara las actas de dicha visita, lo qual, sabido por el arzobispo, embió a su visitador. Y no contentos con el desacato de auerle puesto presso al notario, viendo que el visitador iba acompañado de algunos armados tocaron a rebato y se sublebó el pueblo contra dicho visitador y los que le acompañaban, que tubieron por bien el salir huyendo de dicha villa, pues algunos del pueblo se propasaron hasta tirar piedras contra el coche del arzobispo $^{11}$.

De este modo, el ordinario tuvo que reconocer que tanto esa colegiata, como las de Castrojeriz y Cervatos, no cejaban en su empeño de avance jurisdiccional y mantenían abiertos una serie de pleitos a fin de que el rey les concediese diferentes pretensiones. Fue por ello que el arzobispo llegó a suplicar que

no les conceda cosa alguna en perjuicio de esta jurisdicción ordinaria o que aora, o en algún tiempo pueda darles motiuos de pleitos, más de los que mi dignidad ha tenido y actualmente tiene con dichos abades, y la misma súplica hago a la Santa Sede y a los Eminentísimos y Reuerendísimos Señores Cardenales por si recurriesen a Roma dichos abades como se puede temer recurran ${ }^{12}$.

Entendía, por lo tanto, que solo con el hecho de escucharles «sería vastante para conmover otra vez los ánimos y volver a los escándalos pasados» ${ }^{13}$.

9 AAV, Congr. Concilio, Relat. Dioec., caja 156, f. 212r. Visita de 1754.

10 aguilar de Campoo. Archivo Parroquial de San Miguel de aguilar de Campoo [=APSMAC], Carpeta Varios, doc. 13.

11 AAV, Congr. Concilio, Relat. Dioec., caja 156, ff. 212r-v. Visita de 1754.

12 AAV, Congr. Concilio, Relat. Dioec., caja 156, f. 212r. Visita de 1754.

13 Id., f. $213 \mathrm{v}$. 


\section{LOS SUCESOS DE 1748}

Una realidad que hay que tener muy presente es que no todos los enfrentamientos jurisdiccionales se dirimieron en los tribunales de justicia, sino que hubo ocasiones en que la tensión llegó a picos tan elevados que se desencadenaron situaciones en las que se optó por el uso y empleo de la violencia. En la historia de la colegiata de Aguilar hubo tres momentos culmen en que estos conflictos jurisdiccionales excedieron los límites puramente judiciales y alguna de las partes decidió romper las reglas del juego e intentar obtener una solución a sus problemas recurriendo a unos cauces poco ortodoxos: en 1571, con la prisión del abad Sebastián de la Pinta impuesta por el prelado burgalés; en torno a 1651 -aunque en este caso se pudo reconducir la situación desde los tribunales con una victoria incontestable por parte de la colegiata- y en 1748. De esos tres momentos el último fue, sin duda, el de mayor gravedad de cuántos se vivieron en la institución colegial, provocando unas consecuencias que dinamitaron las relaciones, nunca del todo pacíficas, que se tenía con la mitra burgalesa.

Esta fue la muestra perfecta de cómo los excesos no solo partieron de la dignidad episcopal de Burgos, sino que la colegiata defendió -en ocasiones con demasiado celo- las prerrogativas que creía poseer y que decía emanaban de la bula de erección de $1541^{14}$. De esta manera se llegó a una situación límite en 1748 cuando el cabildo en pleno se negó a aceptar los mandatos que había impuesto el arzobispo Pedro de la Cuadra durante su visita pastoral a la institución que tenía, además, un carácter de urgencia, pues ni la colegial, ni la villa, ni sus feligreses habían recibido la visita de prelado alguno ni administrado el sacramento de la confirmación desde $1719^{15}$.

En esa visita, además, el arzobispo se había encontrado con no pocas sorpresas, de las que ya en parte había sido advertido por su secretario, Bernabé Antonio de la Canal ${ }^{16}$. Un enfrentamiento abierto dividía al cabildo en un desacato

14 Esta bula fue conseguida en 1541 gracias a la mediación del III marqués de Aguilar de Campoo quien, por esas fechas, desempeñaba el cargo de embajador extraordinario del emperador Carlos $\mathrm{V}$ ante los Estados Pontificios. En virtud de esta bula la Casa de Aguilar obtuvo el patronato perpetuo sobre la institución colegial, estando entre sus poderes el de poder nombrar de forma directa a las cuatro dignidades: abad, maestrescuela, chantre y arcipreste.

15 Burgos. Archivo Diocesano De Burgos [=ADB], Colegiatas-Abadías, Aguilar de Campoo, caja 2, cajón $3^{\circ}$, leg. $1^{\circ}$, n. ${ }^{\circ} 30$, f. 1 r.

16 En una misiva que envió al arzobispo el 2 de marzo de 1748, tras haberse adelantado a la llegada del prelado para preparar la visita pastoral, señaló que había detectado en la villa de Aguilar «vicios, excesos, deshórdenes y malas costumbres [...] entre eclesiásticos y seculares» (Id., n. ${ }^{\circ}$ 19, f. 1r). 
manifiesto ante la primera dignidad, los mandatos de las visitas anteriores no se cumplían ${ }^{17}$ y la aplicación de los preceptos del ceremonial se trataban con escasa diligencia ${ }^{18}$. Todo ello hizo que el prelado trabajase con verdadera dedicación para llevar a buen término la reforma de esta institución colegial, dando como resultado de ello la aprobación de treinta capítulos o mandatos de visita. Sin embargo, de manera inmediata el cabildo en pleno, ahora sin fisuras, se posicionó en contra de tales medidas. El día 1 de abril de 1748, con la visita aún en proceso, solicitaron al propio arzobispo Cuadra que reformase ocho capítulos por considerarlos contrarios a la bula de erección de la colegiata, a las concordias que habían realizado entre ambas partes y a los estatutos de la iglesia ${ }^{19}$. Señalaron, de igual modo, que de no estimar estas apelaciones solicitarían, como así sucedió finalmente, el auxilio de la Nunciatura.

Consciente de la reticencia que cualquier intervención externa generaba en la colegial de Aguilar, el arzobispo pensó que enviando a un notario a requerir la documentación precisa sobre la visita y aquella otra que justificase su negativa al cumplimiento de los mandatos se ganaba el tiempo suficiente para que finalmente los ánimos se calmaran y el cabildo decidiese, por fin, cumplir con unas cuestiones que desde Burgos se entendían vitales, y que afectaban no solo a aspectos jurisdiccionales, sino también de ceremonial y de moral ${ }^{20}$.

No obstante, las cosas no salieron como se habían planeado y la presencia de este escribano únicamente sirvió para provocar una respuesta más airada por parte del cabildo y de su abad. El 8 de noviembre el notario receptor de la audiencia arzobispal, Ángel Ruiz de Ogarrio, realizó una requisitoria al abad y notificó en persona a los archivistas de la colegial la obligatoriedad de la entrega

17 En especial, el arzobispo Cuadra se quejó de la falta de cumplimiento de los mandatos impuestos por uno de sus antecesores, Manuel Francisco de Navarrete, en las visitas que realizó en 1710 y 1719, siendo abad Francisco de Iztegui. Es cierto que muchas de las órdenes dadas por ese prelado fueron incumplidas y algunas, incluso, llevadas ante el tribunal de la Nunciatura por el cabildo de Aguilar. Sin embargo, es preciso señalar que estas dos visitas fueron las que mayor rastro y grado de aceptación dejaron en la colegiata de Aguilar. Quizás el símbolo más visible de ello sea la aprobación y reforma de las reglas que decretó el 5 de mayo de 1710, añadiendo diez puntos nuevos que se incorporaron a este documento normativo vital en la vida de la institución. En ellos se trataron aspectos de tanta importancia como el decoro en las actuaciones de los capitulares, la adecuación de ciertas prácticas al ceremonial romano, el trato debido a los presos de la audiencia, el disfrute de los conocidos como post mortem, etc. APSMAC, Reglas y Estatutos de la colegiata, ff. $135 \mathrm{v}-136 \mathrm{r}$.

18 APSMAC, Carpeta Varios, doc. 13, f. 1v.

19 Id., f. 2 r.

20 ADB, Colegiatas-Abadías, Aguilar de Campoo, caja 2, cajón $3^{\circ}$, leg. $1^{\circ}$, n. ${ }^{\circ} 30$, s. f. 
de la documentación requerida ${ }^{21}$. Sin embargo, lo que obtuvo el enviado del arzobispo no fue lo esperado. El abad, Alonso Ramírez Calderón, decidió ordenar la excomunión y la prisión de Ogarrio en la torre de la iglesia ${ }^{22}$ debido a que había intentado «rovar y atraer a él jurisdición que no le ttoca por ningún prettexto» ${ }^{23}$.

Le conduxeron y pusieron preso en la torre de dicha colegial, con grillos y una cadena de peso de más de siete arrobas y a un mismo tiempo por público excomulgado practicando con él otras extorsiones ignominiosas, usurpativas de la jurisdicción privativa del arzobispo, que le obligaron por redimir su vejación a condescender con lo que quería dicho Guerra ${ }^{24}$.

El propio Ogarrio fue quien dio noticia de su privación de libertad por carta a Juan Gutiérrez de Solórzano, vicario de Orbó, el 10 de noviembre de ese mismo año ${ }^{25}$. Por su parte, el abad justificó su negativa a hacer entrega de la documentación requerida porque consideraba que tal petición iba absolutamente en contra de

la exempción de que goza dicho Ylustre Cavildo y sus yndividuos por la bulla de erección de dicha collegial, condedida por la santidad de Paulo ttercero de feliz recordación, concordattos en su virtud con la dignidad arzovispal y contra la jurisdicción que por la expresada bula se concede a dicho señor abad y en cuya posesión está ${ }^{26}$.

21 APSMAC, Carpeta Varios, doc. 13, f. 3r. Principalmente lo que se solicitaba era la entrega, en un plazo de 24 horas, de los libros de visita para la compulsa de las visitas realizadas por los arzobispos Navarrete y Cuadra.

22 ADB, Colegiatas-Abadías, Aguilar de Campoo, caja 3, cjón $3^{\circ}$, leg. $1^{\circ}$, n. ${ }^{\circ}$ 31, f. 8v. El auto de prisión y de excomunión fue dado el 10 de noviembre de 1748 y hecho público por uno de los curas de la colegial, Bartolomé García. El 14 de noviembre el abad dio un auto nuevo con el que permitió al reo salir de la torre, pero le confinó en otra de las prisiones eclesiásticas de Aguilar, la conocida como Casas del Cabildo, donde en ese momento vivía Pedro de Alvarado, sacristán mayor de San Miguel. Id., f. 24r.

23 Id., f. 16r.

24 Id., n. ${ }^{\circ}$ 30, s. f. El 12 de noviembre se tomó confesión al reo por parte del provisor en el propio cuarto de Santo Tomé, en la torre de la colegiata, una prisión de gran dureza para un hombre de cincuenta y tres años. Las preguntas que realizó Jacobo Guerra versaron principalmente sobre asuntos jurisdiccionales. Aunque quiso que el reo reconociese la jurisdicción plena de la audiencia abacial, especialmente en materia criminal, Ángel de Ogarrio supo zafarse, al menos en un principio, arguyendo que había visto en la audiencia arzobispal apelaciones en esta materia. Aunque finalmente hubo de reconocer que nunca había visto en el tribunal diocesano una causa en contra de los capitulares de la colegiata en primera instancia, dando validez a la protección de su fuero eclesiástico y, por lo tanto, quedando en un aprieto por haber llevado una comunicación al abad que no era de su competencia. ADB, Colegiatas-Abadías, Aguilar de Campoo, caja 3, cajón $3^{\circ}$, leg. $1^{\circ}$, n. ${ }^{\circ} 31$, ff. 13v-18v.

25 APSMAC, Carpeta Varios, doc. 13, f. $3 \mathrm{v}$.

26 ADB, Colegiatas-Abadías, Aguilar de Campoo, caja 3, cajón $3^{\circ}$, leg. $1^{\circ}$, n. ${ }^{\circ}$ 31, f. 2r. Copia de un acuerdo capitular celebrado en la colegiata de Aguilar el 9 de noviembre de 1748. Como medio para protegerse de injerencias diocesanas el procurador del cabildo escribió al nuncio y le recordó 
El arzobispo, siendo consciente de lo delicado de la situación, consideró, en un primer momento, que el uso de la fuerza sería contraproducente para sus intereses, por lo que optó por fórmulas puramente eclesiásticas con las que intentar convencer al abad de Aguilar de que dejase de cometer actos tan deleznables. Para ello decidió enviar ante el abad y su provisor al vicario del arciprestazgo, Juan Gutiérrez Solórzano -cura de Orbó y capellán de la colegial ${ }^{27}$-, acompañado de Francisco de Lurarriaga -notario y oficial mayor de la audiencia arzobispal- para que trasladase la misma petición que con anterioridad había llevado el notario que en esos momentos se encontraba atado con grillos a la pared de la celda de la torre de la colegiata. Al no dar resultado, se optó, por parte del fiscal del arzobispo, por ordenar que se liberase de inmediato a $\operatorname{Ogarrio}^{28}$, se declarasen nulas las censuras que en contra de su persona había impuesto el abad y se diese comisión al vicario para que prendiese a Jacobo Guerra, el provisor de la audiencia abacial ${ }^{29}$.

Para su ejecución, y dado que su enviado estaba en prisión, decidió recurrir a las autoridades locales de Aguilar de Campoo. Tanto Solórzano como Lurarriaga presentaron las letras auxiliatorias al corregidor de la villa, Andrés Antonio de Cañabate, quien únicamente se comprometió a impedir al provisor de Aguilar que prendiese a los nuevos emisarios, como había amenazado hacer ${ }^{30}$. Para ello, además, se les recomendó por distintas autoridades hacer noche en la casa del propio corregidor, pues el provisor había dado orden de cercar dicha vivienda como medida de presión.

Hay que señalar, sin embargo, que la perseverancia del vicario y del notario fue notable. Al día siguiente de nuevo intentaron que el corregidor les prestara su auxilio, aunque volvió a negarse, produciéndose en consecuencia un episodio poco afortunado. Esa misma mañana accedieron a la vivienda del corregidor tanto

el poder que tenía en primera instancia la audiencia presidida por el abad de Aguilar, que ni los arzobispos ni los provisores de Burgos podían menospreciar «ni aún en segunda por la omnímoda exsempción y abssolutta de la expresada bulla que litteralmente ttiene recivido vajo la protección de la Sede Apostólica a dicho cavildo clásusula exclusiba de yntroducción de los ylustrísimos señores arzovispos de Burgos» (Id., f. 5r).

27 Esto suponía, en realidad, un grave problema jurisdiccional. Es cierto que Solórzano actuaba como vicario del arzobispo de Burgos, pero al ser capellán de la colegial estaba sometido al fuero y a la justicia en primera instancia del abad de San Miguel. De este modo, el propio abad le recordó en el transcurso de estas negociaciones que le debía obediencia.

28 Esta liberación no se produjo hasta el día 17 de noviembre, con la orden de abandonar la villa y con el apercibimiento por parte del provisor de Aguilar de mayores apremios si decidía retornar la causa por cuestiones de carácter jurisdiccional.

29 APSMAC, Carpeta Varios, doc. 13, f. $3 \mathrm{v}$.

30 Id., f. 5 r. 
Jacobo Guerra como el notario de su audiencia, Ignacio Caballero, con la intención de exigir explicaciones a los enviados diocesanos. Estos, en cambio, no solo no reconocieron al provisor como juez, sino que se le impelió a darse por reo de la autoridad de Burgos y se llegó, incluso, a unos conatos de violencia entre los clérigos. La situación se resolvió con la intervención de los ministros del corregidor de Aguilar que, ante la orden de Jacobo Guerra, terminaron por prender también al vicario y al notario y encerrarlos en la torre de la colegial que hacía las veces de cárcel eclesiástica ${ }^{31}$. Con este acto estaban dando cumplimiento a un auto del abad en el que exhortaba el auxilio del brazo seglar, especialmente del corregidor, que no era sino la justicia ordinaria nombrada por los marqueses de Aguilar $^{32}$.

No obstante, y según los testimonios de aquellos que presenciaron este suceso, el trato que se dispensó a estos presos no estuvo en sintonía con el decoro que se debía a alguien de su posición, ya que se les arrestó

arrastrándoles por la escalera de dicho corregidor y profiriendo don Juan González de Terán, canónigo que se hallaba a la puerta de dicha colegial cuando iban presos, voces tráiganme aquí esos perturbadores de la paz, usurpadores de las regalías y exenciones de esta iglesia ${ }^{33}$.

Es decir, en esta ocasión, como ya ocurrió en los sucesos de 1571 -y otras muchas veces-, el corregimiento de la villa de Aguilar se posicionó junto con el cabildo eclesiástico y desoyó las órdenes que desde Burgos clamaban por la liberación de su notario y la restitución de la paz en esa villa y en toda la diócesis. Por ello, el arzobispo entendió que el corregidor Andrés Antonio de Cañabate,

coligado sin duda con dicho abad, Guerra y otros díscolos canónigos, con figurados pretextos se escusó a darlas cumplimiento e impartir el auxilio que se le pedía, deteniendo en su propia casa a los referidos vicario y notario, persuadiéndoles que

31 ADB, Colegiatas-Abadías, Aguilar de Campoo, caja 2, cajón $3^{\circ}$, leg. $^{\circ}{ }^{\circ}$ n. ${ }^{\circ} 31$, ff. 30v-31r. Fue el hermano del vicario, José Gutiérrez de Solórzano, vecino de Aguilar, quien dio aviso de tales sucesos al arzobispo de Burgos el 27 de noviembre de 1748. APSMAC, Carpeta Varios, doc. 13, ff. $5 \mathrm{v}-6 \mathrm{r}$.

32 Esta es una gran muestra de colaboración entre dos autoridades, una seglar y la otra eclesiástica, que debían su posición y su nombramiento al patronazgo señorial. Es por ello que ante este requerimiento el corregidor argumentase que sin perjuicio de la jurisdicción real se encontraba presto para darle el auxilio que necesitase. ADB, Colegiatas-Abadías, Aguilar de Campoo, caja 3, cajón $3^{\circ}$, leg. $1^{\circ}$, n. ${ }^{\circ} 31$,ff. 30v-32r.

33 APSMAC, Carpeta Varios, doc. 13, f. 5v. Como represalia de estas acciones el chantre de la colegiata, Miguel Bravo de Villalobos, fue mandado detener por el arzobispo de Burgos y puesto preso en la cárcel de Villadiego el 6 de diciembre de 1748. 
si salían de ella los prendería dicho abad, lo que facilitó, pues teniéndolos cerrados en dicha su casa, dio lugar y permitió el que entrando en tropel el expressado Guerra, con otros canónigos, criado del abad, sacristán y organista, se arrojassen en su presencia sobre dichos vicario y notario y los llevasen arrastrando a dicha torre, con la propia ignominia que al notario antecedente, en la que les tuvieron privados de toda comunicación desde el día veinte y siete de noviembre hasta seis de diciembre de dicho año próximo passado en que por haver enfermado el mencionado notario por lo riguroso de la prisión y estación, le removieron a la casa de don Joseph García del Barrio, eclesiástico, sobrino del abad y a dicho vicario a la del cabildo ${ }^{34}$.

La persona que orquestó todo este movimiento de resistencia no fue, sin embargo, el abad de la colegial, sino el maestrescuela y provisor, el ya citado Jacobo Guerra quien, en palabras del arzobispo, se hizo «dueño de toda jurisdicción eclesiástica y secular de dicha villa $\gg^{35}$. Por ello, la querella principal y la orden de prisión emitida desde Burgos fue en contra de Jacobo Guerra y de los canónigos Francisco Herrero, Pedro de Soto y José del Barrio por su carácter de perturbadores y por haber usurpado la jurisdicción privativa del arzobispo ${ }^{36}$.

Como se puede apreciar, los excesos por parte de la villa de Aguilar fueron tan notorios que lógicamente acarrearon consecuencias de mayor nivel. Después de una petición de la mitra la Chancillería de Valladolid ordenó que se restituyese la paz y que en Aguilar volvieran a la obediencia de su prelado. El arzobispo, por su parte, tampoco estuvo ocioso y decidió promulgar una serie de excomuniones en contra del provisor y otros canónigos díscolos que, como no se quisieron publicar por los curas de la colegial, hubo de hacerse en la parroquia de Santa María la Real ${ }^{37}$.

Ante esta situación de desamparo, desde la sede episcopal se pidió el auxilio del brazo seglar, al que acudió presto el alcalde mayor de Burgos. Este actuó respaldado por la autoridad de una real auxiliatoria expedida por la Chancillería de Valladolid el día 6 de diciembre, mediante la que se autorizó al cura José Rubí, del lugar de Fuencaliente, a que acompañara al teniente corregidor de Burgos -Tomás Alonso de Tejada- «con tropa militar» y demás personas para que pasasen a la villa de Aguilar. La misión estaba clara: sacar de prisión al vicario y al notario y recoger los autos originales que contra ellos se habían formado y que los archi-

34 ADB, Colegiatas-Abadías, Aguilar de Campoo, caja 2, cajón $3^{\circ}$, leg. $1^{\circ}$, n. ${ }^{\circ} 30$, s. f.

35 Ibidem.

36 APSMAC, Carpeta Varios, doc. 13, f. 4v.

37 La declaratoria fue en contra del abad, del maestrescuela, de los canónigos Herrero, Soto e Ibáñez y del corregidor, y se publicaron, además de en el monasterio, en la parroquia de San Andrés -extramuros de la villa- y en Cillamayor. Id., f. 6v. 
vistas de la colegial se negaban a entregar ${ }^{38}$. Además, se pidió que compulsasen las visitas y que recibiesen la justificación precisa de los «perturbadores» para que, en caso de resultar culpables, fueran llevados como reos a la cárcel arzobispal.

No obstante, cuando este grupo ${ }^{39}$ llegó a la casa del corregidor de la villa el día 8 de diciembre descubrieron que los ánimos no estaban calmados y que la puesta en libertad de los presos y el restablecimiento del orden no iba a ser tarea fácil. Ya al entrar en la villa «oyeron tres campanadas y consecutivamente tocar a arrebato y a la puerta de dicha iglesia mucha gente y por las bocacalles venían hombres, mujeres y niños $\gg^{40}$. Una situación que fue considerada por las autoridades eclesiásticas de Aguilar como una «armada invasión» y que se intentó repeler con el toque de campanas y la sublevación de la población. La táctica, de nuevo, fue orquestada por el provisor Guerra con la intención de rodear la casa en la que se encontraba el teniente de corregidor de Burgos al que, sin éxito, se intentó prender mientras pretendía que se aplicase la Real Provisión que había dado la Chancillería de Valladolid ${ }^{41}$. Solo se evitó su apresamiento debido a la rápida intervención de seis ministros del Resguardo de la Renta del Tabaco que había llevado como compañía para su asistencia.

Aun así, los capitulares de Aguilar no estaban conformes con la situación y con la presencia de esas autoridades foráneas por lo que volvieron a tocar las campanas a rebato y sublevaron de nuevo a toda la plebe de la villa con el argumento de que se «les quería quitar la patrimonialidad de los canonicatos» ${ }^{42}$. Unos hechos que provocaron nuevos episodios de violencia, especialmente cuando el capitán de la guardia, Rafael de Briones -del regimiento de milicias de Burgos-, bajó a la plaza pública a intentar calmar los ánimos pues había «mucha gritería que se dijo de ser de gente armada y que de la torre tiraban cantos» ${ }^{43}$. Pero,

sin oírle sus razones le metieron preso en la iglesia donde le dejaron cerradas las puertas y con ímpetu intentaron entrar en dicha casa del alcalde mayor, a no haberlo resistido los guardas y bajado dicho alcalde mayor para sosegar la gente ${ }^{44}$.

38 Id., f. 8v.

39 El grupo estaba compuesto por el teniente de corregidor, José Ruiz en calidad de auxiliado, seis guardias de la Renta de Tabaco, un capitán, dos soldados, don Pedro Pablo de Vera -visitador y defensor de la dignidad arzobispal-, un escribano, un notario, un alguacil y varios criados. Ibid.

40 Id., f. $9 \mathrm{v}$.

41 ADB, Colegiatas-Abadías, Aguilar de Campoo, caja 2, cajón $3^{\circ}$, leg. $^{\circ}$, n. $^{\text {o } 30, ~ s . ~ f . ~}$

42 Ibidem.

43 APSMAC, Carpeta Varios, doc. 13, f. 9v.

44 Ibid. En el testimonio que se tomó con posterioridad al capitán se puede observar la enorme tensión vivida en esos días de diciembre. El capitán señaló que cuando bajó de la casa del corregidor de Aguilar a la plaza vio a dos canónigos pidiendo a gritos auxilio para la iglesia y que uno de 
La confusión, por lo tanto, fue total.

Había en la plaza mucha jente y venían otras por las vocacalles y portales como hombres, mujeres y muchachos con espadas, escopetas, trabucos, pistolas, lanzas, dagas, alabardas, espontones, hachas de armas, chuzos y palos con tal confusión azia la yglesia ${ }^{45}$.

Una situación que provocó que, de nuevo, las autoridades de Aguilar negasen el auxilio, en esta ocasión pretextando que la provisión no tenía la fuerza suficiente por no provenir del rey o de su cámara. Idéntico argumento se escuchó de los sublevados que gritaban por las calles que «habían de defender la iglesia hasta perder las vidas» $\mathrm{y}$ «que no habían de parar las gentes hasta prender al de la capa de grana, que era dicho teniente de corregidor» ${ }^{46}$. Incluso, fueron provocando

a los ministros de la Ronda, diciendo quien mató al conde, Fuente Ouejuna, y que tiraron algunas piedras al coche del señor arzobispo y que si este hubiera hido a dicha villa le hubieran preso y que la respuesta dada por el correjidor ha sido dispuesta por el abad, maestrescuela y canónigos, infiriéndolo de hauer llegádose a la yglesia donde estaua Bentura Ybáñez con un papel y buelto con él a cassa de dicho alcalde maior y que reconozieron ser caudillos animadores y fomentadores de el alboroto dicho Bentura Antonio Ybáñez, un soldado dragón, un procurador hierno del administrador de tabacos de aquella villa, el médico de ella porque a estos los demás les obedecían ${ }^{47}$.

ellos era Jacobo Guerra. Describe cómo se vio acorralado por la gente y cómo tuvo que sacar la pistola. En un primer momento, cuando apuntó con ella a la gente, el tumulto se detuvo y tuvo un encontronazo con algunos de los canónigos. Varios testigos de los sucesos aseguraron después que viendo peligrar por su seguridad llegó a gritar «¿Quién ay que a mí se attreva?», a lo que le respondió un canónigo: «Yo no me attrevo con Vuestra Merced, defiendo mi yglesia, cuias armas son rosarios y oraciones». ADB, Colegiatas-Abadías, Aguilar de Campoo, caja 3, cajón $3^{\circ}$, leg. $1^{\circ}$, n..$^{\circ}$ 31, f. 91r. Finalmente fue rodeado por un grupo comandado por Guerra y el canónigo Marín, le detuvieron y le encerraron en la iglesia quitándole la pistola, la capa, el sombrero y el bastón. Unos objetos que, salvo la pistola, le fueron restituidos. Señala que el alboroto duró unas dos horas y media. Después, fue llevado ante el cabildo que estaba celebrando una sesión extraordinaria y fue reprendido por el abad por haber sacado una pistola y haber amenazado con ella al tumulto. El capitán, en un intento de mediar quiso suavizar la situación solicitando al abad que soltase a los presos, a lo que el abad se negó, entre otras cosas, porque aún no había oído misa, invitando momentos después al capitán a comer a su propia casa.

45 APSMAC, Carpeta Varios, doc. 13, f. 10r.

46 Ibidem.

47 Id., f. 11 r. 
Ante esta complicada situación, y apedreado por la plebe, el alcalde mayor de Burgos no tuvo más remedio que salir huyendo de la villa de Aguilar, máxime, cuando fue informado de que los amotinados estaban haciendo rondas y ante el rumor de que se acercaba el arzobispo en persona se habían vuelto a soliviantar poniendo, incluso, atalayas de vista en el castillo de la villa y otras partes para tener controlados todos los accesos al casco urbano ${ }^{48}$. Esta humillación, y los actos vandálicos que se habían vivido, provocó que el arzobispo promulgase un edicto de excomunión general y que se decidiera por buscar el auxilio de las más altas instancias, comenzando con una queja ante el rey con la intención de que se pusiera fin a un desacato «tan grave y pocas veces visto» ${ }^{49}$

como han cometido dicho abad y canónigos los horrendos sacrilegios, tumultos y excesos que sublevando aquella filegresía y pleve de SSY y usurpando toda su athoridad jurisdición episcopal y cura de almas y velipendiando su sagrada persona y ministerios son tan notorios como ynaudittos y escandalosos ${ }^{50}$.

\section{LA INTERVENCIÓN DEL PATRONAZGO}

Viendo el absoluto desastre que se estaba produciendo en la villa de Aguilar, que se tenía a la población sublevada en armas, al cabildo y al corregimiento en pie de guerra y que se estaban desacatando órdenes de la Chancillería y del Consejo de Castilla ${ }^{51}$, se entendió que solo la intervención directa del marqués de Aguilar -«como patrono de aquella iglesia, dueño y señor de la villa»- podría poner fin a ese sinsentido y permitir que la situación se normalizase. Los cauces de resolución de conflictos entre las diferentes jurisdicciones eclesiásticas no habían funcionado, por lo que se requería la intervención de otro poder, esta vez

48 Id., f. 13r. Estas rondas continuaron durante los días 10 y 11 de diciembre y estuvieron dirigidas por el corregidor. Además, se mantuvo la taberna abierta hasta las 12 de la noche para llevar pellejos de vino a la casa del ayuntamiento donde seguía congregándose mucha gente.

49 ADB, Colegiatas-Abadías, Aguilar de Campoo, caja 2, cajón $3^{\circ}$, leg. $1^{\circ}$, n. $^{\circ} 30$, s. f.

50 Id., caja 3 , cajón $3^{\circ}$, leg. $1^{\circ}$, n. ${ }^{\circ} 31$, f. $334 \mathrm{v}$.

51 Esta intervención estaba perfectamente justificada y contemplada en el ordenamiento jurídico castellano, ya que, «los reyes de Castilla de antigua costumbre, aprobada y usada y guardada, pueden conocer y proveer de las injurias, violencias y fuerzas que acaecen entre los prelados y clérigos y eclesiásticas personas sobre las iglesias y beneficios». Una regalía que quedaba delegada en el Real y Supremo Consejo de Castilla, como protector de la disciplina y del Sagrado Concilio de Trento. José de CovarRubias, Máximas sobre recursos de fuerza... [ver n. 1], pp. 204-205. 
de carácter señorial ${ }^{52}$. No en vano tanto el abad como el corregidor eran personas dependientes del marqués y le debían obediencia y respeto en virtud de su derecho de patronazgo ${ }^{53}$. Un derecho que se había convertido en un elemento absolutamente fundamental para comprender los valores nobiliarios de Castilla durante el Antiguo Régimen. De este modo, en una sociedad sacralizada y completamente imbuida por los valores religiosos, era cuestión de lógica que estos nobles orientasen sus deseos de poder, de patronazgo y de protección hacia las esferas eclesiásticas, aunque no solo ${ }^{54}$.

El concepto de patrón o patrono apunta a protección, a defensa y amparo, pero también remite a nociones de poder y superioridad [...]. El patronazgo vino a formar parte de las cualidades de la nobleza: destilaba preeminencia, supremacía, distinción, magnanimidad, paternalismo, piedad...atributos todos ellos que se pretendieron característicos y propios de la nobleza y los señores ${ }^{55}$.

Así pues, y ante una situación realmente comprometida en el seno de su señorío jurisdiccional, el marqués,

haciéndose cargo de todo lo que se cuestionaba y que estas incidencias criminales nada podían adelantar a unas ni otras partes y la buena correspondencia que siempre había tenido su Casa con los señores arzobispos de Burgos y por su propensa inclinación a la paz y a que como prelado era razón se le tributase la mayor atención, pudo con su autoridad proporcionar medio para cortar los debates criminales ${ }^{56}$.

Su intervención, y la estructura de poder que tenía desplegada en la villa de Aguilar de Campoo y su jurisdicción fueron decisivas. El marqués no podía tolerar esas muestras de violencia y menos aún una insurrección abierta en contra de un prelado de la Iglesia. Así pues, ordenó al cabildo que cejase en su empeño criminal y, además, que cumpliese ciertas partes de los mandatos pastorales, es-

52 Id., f. $336 \mathrm{v}$.

53 José Antonio JARA FUENTE, Para sujetar a vasallos rebeldes (Jurisdicción y control señorial en la España del siglo XVIII), en Anuario de historia del derecho español, 62 (1992), pp. 593-622; María LóPEZ DíAz, La administración de la justicia señorial en el antiguo régimen, en Anuario de Historia del Derecho español, 76 (2006), pp. 557-588.

54 Ángela ATIENZA LÓPEZ, La apropiación de patronatos conventuales por nobles y oligarcas en la España Moderna, en Investigaciones Históricas, 28 (2008), p. 79.

55 Ibidem.

56 ADB, Colegiatas-Abadías, Aguilar de Campoo, caja 3, cajón 3º leg. $1^{\circ}$, n. ․ 31, f. 336v. 
pecialmente aquellas tendentes al cumplimiento de las buenas costumbres, a la corrección de vicios, pagos de derechos, formalidad en el cumplimiento de los oficios divinos y otros piadosos fines, puesto que entendía que eso solo podía redundar en beneficio de su iglesia colegial.

Igualmente, dispuso que debían acudir a Burgos dos representantes del ayuntamiento y dos del cabildo eclesiástico, a poder ser los motores de los disturbios, a solicitar el perdón del prelado de Burgos con el fin de «restablecer la buena armonía y sumisión que en sus respectivos casos se debe tener a la Curia $\gg^{57}$. El deseo del marqués de que la situación se restableciese definitivamente quedó patente en una misiva enviada al arzobispo el 29 de septiembre de 1749 en la que pretendía el perfecto restablecimiento de su colegial y anunciaba que dos de sus prebendados irían a manifestar ante el ordinario los deseos de que se indultase a todos los individuos del agravio que «cualquier inadvertencia haya motivado a los ministros enviados por Vuestra Ilustrísima, respecto de la veneración con que miran su dignidad $\gg^{58}$.

Además, de esta forma se podría poner fin a los gastos que se estaban produciendo en la consiguiente disputa judicial dirimida en diferentes instancias judiciales como eran la Chancillería, la Nunciatura o el Consejo de Castilla ${ }^{59}$. Una sumisión que se llevó a cabo por parte del cabildo el 17 de octubre de 1749 cuando el chantre, Miguel de Villalobos, y el canónigo Pedro de Soto Manzanedo se presentaron ante el arzobispo y solicitaron su perdón en una audiencia pública en presencia del deán y del cabildo catedral ${ }^{60}$. De igual manera, el marqués obligó a acudir en busca del perdón del ordinario a dos representantes de su villa de Aguilar, Juan Antonio de Salceda y Miguel Gutiérrez, regidores del concejo. En una nueva misiva del marqués al arzobispo se interesó en que lograsen «esta gracia, no dudo se la fazilite la atención que merezco a Vuestra Ilustrísima respecto de la que me promete su favor» ${ }^{61}$. Por último, en febrero de 1750 , fue Jacobo Guerra

57 Id., f. $337 \mathrm{r}$.

58 Id., f. 345r-v.

59 En el Archivo Parroquial de Aguilar de Campoo han quedado sobradas muestras de lo que estos procesos supusieron en cuanto a gastos, con numerosos viajes tanto a Burgos como Madrid por parte de canónigos y dignidades. Así, en 1750 -en los últimos coletazos de este proceso- Jacobo Guerra y José Gregorio Marín gastaron en sus viajes a Madrid y en procedimientos varios en torno a 5.000 reales. APSMAC, Cuentas y Recibos 1712-1902, doc. 193, f. 1r. Aunque ya en 1749 se habían gastado en un primer viaje a Madrid 1.341 reales (Id., doc. 196, f. 1r y ss) y en un segundo en el que aparece detallada cada partida de gasto con los trayectos, tiempo, pecios, comidas..., 4.343 reales (Id., doc. 195, f. 1r y ss).

60 ADB, Colegiatas-Abadías, Aguilar de Campoo, caja 3, cajón $3^{\circ}$, leg. $^{\circ}$, n. ${ }^{\circ} 31$, f. 347 r.

61 Id., f. 348r. Carta dada en Madrid el 19 de septiembre de 1749. 
quien tuvo que solicitar el indulto del arzobispo, también con la intercesión del patrono de la colegial ${ }^{62}$.

Sin embargo, y pese a esta decidida actuación, el marqués no estaba dispuesto en modo alguno a que los poderes jurisdiccionales que beneficiaban a su iglesia colegial siguieran siendo puestos en duda por la autoridad diocesana, por lo que pidió al arzobispo con contundencia que observase y respetase la jurisdicción del abad, es decir, pidió que se observasen los autos de visita pero «con separación de los puntos de jurisdicción ni demás que toca a las regalías y honores del abad, su iglesia y cabildo que estos se deben separar de la causa criminal $\gg^{63}$.

La dignidad arzobispal, no obstante, quedó realmente asombrada por los sucesos y por las violencias que se habían desatado en Aguilar donde canónigos y dignidades se habían enfrentado a sus enviados y habían espoleado a la población que, equipada incluso con armas de fuego, había salido en defensa de unos derechos que asumían como propios. Incluso, mostró su desacuerdo hacia unas letras del nuncio ganadas a instancias de la colegiata el 5 de febrero de 1749 pues entendía que

son y han sido expedidas sobre un falsísimo supuesto y sobre causa e inzidentes que inivisos de ella ai pendientes en el tribunal de dicho señor nuncio ni de ella y procedimientos del arzobispo mi señor se apelado por los canónigos de Aguilar ni presentado testimonio de haverlo hecho como se reconoze de la misma falsa siniestra relación con que se han ganado ni para haver apelado tenían ni podían tener motivo ni mucho menos para haverse juntado en conziliábulo y por medio de él cometer como han cometido dicho abad y canónigos los horrendos sacrilegios, tumultos y excesos que sublevando aquella filegresía y pleve de SSY y usurpando toda su athoridad jurisdición episcopal y cura de almas y velipendiando su sagrada persona y ministerios son tan notorios como ynaudittos y escandalosos además de constar del processo sin embargo de todo lo qual y de la nulidad con que se han expedido dichas letras de yniuición las obedecía y obedeció dicho señor ilustrísimo por aora y sin que por esto sea visto consentir se vulnere su primera ynstancia ni los respectos de su Sagrada dignidad ajada, desobedecida y vituperada por dicho abad y canónigos ${ }^{64}$.

El impacto de estos sucesos quedó reflejado en un informe que realizó el arzobispo a lo largo de 1749 en el que se daba cuenta de estos y otros conflictos a petición del Consejo de Castilla. Un informe que se había solicitado con la inten-

\footnotetext{
62 Id., f. 349r.

63 Id., f. 337 r.

64 Id., f. 334r.
} 
ción de saber si la situación realmente se habían calmado, para que informase si tenía algún problema con su cabildo catedral o con otros cabildos de su diócesis y para que propusiera los medios más adecuados para reinstaurar una paz y concordia que se creía más que conveniente para el sosiego del estado eclesiástico ${ }^{65}$.

Así, en un largo argumentario, explicó lo sucedido y culpó directamente al abad y canónigos de la colegial, aunque haciendo especial mención en el provisor Jacobo Guerra. Eso sí, en una tónica que se mantendría estable durante todo el proceso, quiso exculpar a la feligresía, no pretendiendo afligirla, sino allanarla y «desengañarla de las falsas imposturas con que la sublevaron» ${ }^{66}$. Solicitó, aun así, que se corrigiese y castigase a los eclesiásticos implicados debido a sus yerros y a los desacatos con que habían ultrajado y vituperado a su propio obispo y pastor ${ }^{67}$. Reconoció, además, que esta situación había desestabilizado la paz diocesana y que ni en su etapa de obispo de Osma ni en esta de arzobispo de Burgos había tenido enfrentamientos como los que se habían producido en Aguilar. Una excepción dentro de una diócesis como la burgalesa en la que, eso sí, reconocía que abundaban más de lo necesario los «cabildos inferiores».

Cumpliendo con lo que se me ordena debo asegurar y expresar a VA que ni con el cabildo de la Santa Yglesia de Osma en el tiempo que tube a mi cargo su govierno ni con el de esta metropolitana se ofreció ni ha ofrecido ni espero en Dios se ofrezca discordia ni pleyto alguno, así porque tengo mui presente del Apóstol como porque he procurado en quanto ha estado de mi parte no dar el menor motivo a disensiones estimando como es razón y debo a este mi cabildo y sus particulares como a mis hermanos y en ellos he experimentado igual correspondencia en todo aquel respeto que es debido a la dignidad.

Por lo que mira a cabildos inferiores de que abunda más que lo necesario y conveniente esta diócesis y que asta el presente he podido visitar personalmente he procurado tratarlos con igual afecto disimulando en ellos las culpables omisiones y contravenciones al cumplimiento de su obligación y mandatos de mis antecesores cuia observancia les estaba intimada, conteniéndome en providencias para lo futuro lo que pareció indispensable para su corrección y enmienda, buena asistencia a las horas y culto divino, observancia de los ritos y ceremonias sagradas, estirpación de abusos, vida, costumbres y decencia del estado.

Esta benigna y moderada conducta con que he procedido en las collegiatas de Castrogeriz, Cervatos y Santander (no incluio la de Santillana en la que solo visité lo perteneciente ad curam aunque no ignore su estado y el de sus llamadas

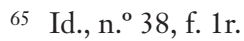

66 Id., caja 2, cajón $3^{\circ}$, leg. $1^{\circ}$, n. ${ }^{\circ} 30$, s. f.

67 Ibidem.
} 
anejas) estoi persuadido que no ha producido la menor queja ni recurso a mi tribunal ni persona pidiendo moderazión o reforma de mis providencias y mandatos a excepción del abbad y cabildo de la collegial de Aguilar que de resulta de la personal visita que no sin grave travajo e incomodidad hice de ella por el mes de marzo del año próximo pasado experimenté contra todo lo que me podía prometer y esperar de la benignidad que usé, tanto con la persona del abbad cabeza de aquel cabildo como con este y sus individuos que se introdugeron dos distintos recursos y en diversos tribunales y sobre distintos mandatos ${ }^{68}$.

Una queja amarga de un arzobispo que decía haber actuado con toda la benignidad posible pero que eso no se había traducido en un cumplimiento de mandatos y censuras con especial dolo por parte del abad al

equivocar y confundir la immediación de su persona a la Santa Sede extra visitationem con la jurisdicción referida y limitada que tiene sugeta a mi tribunal en segunda instancia que es a lo que sin temor de Dios ha aspirado y aspira con transgresión de las censuras y penas ${ }^{69}$.

Pedro de la Cuadra entendió, por último, que solo el envío de emisarios, mejor aún si la comparecencia era hecha por los culpables, y la petición de perdón para que la autoridad episcopal pudiese quedar plenamente reintegrada, sería el camino hacia la paz. Solo así se podría restablecer la concordia entre la dignidad episcopal y «aquel inferior cavildo [...] tan nezesario para el nerbio de la disciplina eclesiástica y que cesse el escánalo y mal exemplo que ha ocasionado aquel cavildo con sus sacrílegos atentados $\gg^{70}$. Eso sí, en última instancia solicitó al Consejo de Castilla que no se tomase ningún tipo de represalia ni medida en contra de la feligresía de Aguilar, a la que el arzobispo descargaba de toda culpa puesto que todo lo que hicieron se debió, según su percepción, al engaño promovido por el cabildo colegial.

\section{CONCLUSIONES}

Los sucesos de 1748 acaecidos en la villa de Aguilar de Campoo son un buen ejemplo con los que observar el funcionamiento de los complicados y, a veces, necesarios equilibrios entre las distintas jurisdicciones de la España mo-

\footnotetext{
68 Id., caja 3 , cajón $3^{\circ}$, leg. $1^{\circ}$, n. $^{\circ} 38$, ff. $1 v-2 v$.

69 Id., f. 4v.

70 Id., f. 9r.
} 
derna. Las interferencias entre unas y otras eran constantes, así como los enfrentamientos, lo que suponía que, en muchas ocasiones, incluso a la justicia del rey le costase poner orden en unas disputas que solían tener unas profundas raíces y que, en el mejor de los casos, se enquistaban en interminables y costosos procesos judiciales.

Cada parte pugnaba duramente por defender los derechos que creía propios e inalienables y cuando el cauce elegido dejaba de lado los instrumentos pacíficos de la justicia reglada el problema se agravaba.

Así sucedió en este caso entre dos instituciones eclesiásticas como fueron la mitra burgalesa y la colegiata de Aguilar de Campoo enfrentadas en lo jurisdiccional, en realidad, desde el mismo momento de la erección de esta última en 1541. Los motivos por los que se creó, así como la amplitud competencial otorgada al abad como primera dignidad, disgustaron enormemente a los prelados de Burgos. La colegiata de Aguilar y su abad fueron, por lo tanto, un elemento desestabilizador en el entorno diocesano ya que, además de sus continuas desobediencias, provocaron cíclicamente enfrentamientos violentos, aunque ninguno como el ocurrido en 1748.

La gravedad del asunto se puede observar en la multitud de instituciones y niveles judiciales que intervinieron para intentar buscar una salida pactada y el retorno a la calma: la audiencia arzobispal y la abacial, la Chancillería de Valladolid, la Nunciatura y hasta el Consejo de Castilla en representación del rey.

Sin embargo, la solución vino de una de esas jurisdicciones especiales del Antiguo Régimen, la señorial, debido a la condición que los marqueses de Aguilar tenían como patronos de la institución. Su poder, y el prestigio y preponderancia que los señores de la Casa de Aguilar tuvieron durante siglos en su villa y en su iglesia, facilitó que su pudiera poner orden dentro de una situación de anomalía. El derecho de patronazgo logró imponer la paz quebrada entre dos jurisdicciones eclesiásticas, medió para buscar la mejor solución, influyó en el arzobispo Cuadra para conseguir que perdonase a los insurrectos e impuso medidas drásticas a los prebendados de su colegiata. Con todo ello se dio por terminado un grave conflicto, aunque, eso sí, ese papel de mediador fue aprovechado por el marqués para reivindicar las exenciones propias de San Miguel.

Su papel fue necesario y de vital importancia, pero no iba a dejar pasar la oportunidad que se le brindaba de poder apuntalar su poder jurisdiccional, perfeccionando la influencia que tenía sobre sus vasallos y delimitando con total claridad, en su favor, como es obvio, los límites entre los poderes eclesiásticos en lucha. 


\section{REFERENCIAS BIBLIOGRÁFICAS}

Archivos

Roma. Archivio Apostólico Vaticano [=Aav], Congr. Concilio, Relat. Dioec.

aguilar de Campoo. Archivo Parroquial de San Miguel de Aguilar de CamPOO [=APSMAC], Carpeta Varios.

Burgos. Archivo Diocesano De Burgos [=ADB], Colegiatas-Abadias, Aguilar de Campoo.

\section{Bibliografía}

ATIENZA LÓPEZ, Ángela, La apropiación de patronatos conventuales por nobles y oligarcas en la España Moderna, en Investigaciones Históricas, 28 (2008), pp. 79-116.

Corada Alonso, Alberto, Burgos: una diócesis en conflicto durante el Antiguo Régimen, en Ofelia Rey Castelao, Rubén Castro Redondo y Camilo Fernández CorTiZO (eds.), La vida inquieta. Conflictos sociales en la Edad Moderna, Santiago de Compostela, 2018, pp. 197-213.

CorADa AlONSO, Alberto, La archidiócesis de Burgos a través de las Visitas ad limina de finales del Antiguo Régimen: gobierno y organización interna, en $\mathrm{M}^{\mathrm{a}}$ Ángeles PÉREZ SAMPER y José Luis BETRÁN MOYA (eds.), Nuevas perspectivas de investigación en Historia Moderna: Economía, Sociedad, Política y Cultura en el Mundo Hispánico, Madrid, 2018, pp. 342-353

CORADA AlONSO, Alberto, Fuero y violencia: el clero capitular ante la Audiencia Abacial de Aguilar de Campoo, en Paula HERNÁNDEZ RODRÍGUEZ et al. (eds.), Las Violencias y la Historia, Salamanca, 2016, pp. 787-809.

COVARRUBias, José de, Máximas sobre recursos de fuerza y protección, con el método de introducirlos en los tribunales, Madrid, 1786.

JARA FUENTE, José Antonio, Para sujetar a vasallos rebeldes (Furisdicción y control señorial en la España del siglo XVIII), en Anuario de bistoria del derecho español, 62 (1992), pp. 593-622.

LÓPEZ DíAZ, María, La administración de la justicia señorial en el antiguo régimen, en Anuario de Historia del Derecho español, 76 (2006), pp. 557-588.

Pacho Polvorinos, Alberto, Edad Moderna, en Bernabé Bartolomé Martínez (ed.), Historia de las diócesis españolas, vol. 20. Iglesias de Burgos, Osma-Soria y Santander, Madrid, 2004, pp. 123-188.

PÉREZ-PRENDES Y MUÑOZ DE ARRACO, José Manuel, El Tribunal eclesiástico (sobre el aforamiento y la estructura de la Curia diocesana de justicia), en Enrique MARTíNEZ RUIZ y Magdalena de PAZZIS PI (eds.), Las jurisdicciones, Madrid, 1996, pp. 143-170.

Rico CALlado, Francisco Luis, La documentación judicial eclesiástica en la Edad Moderna. Estudio diplomático de los fondos diocesanos, Cáceres, 2014. 